\title{
Evaluation of Prostate Cancer with Radiolabeled Amino Acid Analogs
}

\author{
David M. Schuster ${ }^{1}$, Cristina Nanni ${ }^{2}$, and Stefano Fanti ${ }^{2}$ \\ ${ }^{I}$ Department of Radiology and Imaging Sciences, Emory University, Atlanta, Georgia; and ${ }^{2}$ Department of Nuclear Medicine, \\ Policlinico S. Orsola, University of Bologna, Bologna, Italy
}

Conventional imaging of prostate cancer has limitations related to the frequently indolent biology of the disease. PET is a functional imaging method that can exploit various aspects of tumor biology to enable greater detection of prostate cancer than can be provided by morphologic imaging alone. Radiotracers that are in use or under investigation for targeting salient features of prostate cancer include those directed to glucose, choline, acetate, prostate-specific membrane antigen, bombesin, and amino acids. The tumor imaging features of this last class of radiotracers mirror the upregulation of transmembrane amino acid transport that is necessary in carcinomas because of increased amino acid use for energy requirements and protein synthesis. Natural and synthetic amino acids radiolabeled for PET imaging have been investigated in prostate cancer patients. Early work with naturally occurring amino acid-derived radiotracers, such as $\mathrm{L}-{ }^{11} \mathrm{C}$-methionine and $\mathrm{L}-1-{ }^{11} \mathrm{C}-5$-hydroxytryptophan, demonstrated promising results, including greater sensitivity than ${ }^{18} \mathrm{~F}-\mathrm{FDG}$ for intraprostatic and extraprostatic cancer detection. However, limitations with naturally occurring amino acid-derived compounds, including metabolism of the radiotracer itself, led to the development of synthetic amino acid radiotracers, which are not metabolized and therefore more accurately reflect transmembrane amino acid transport. Of the synthetic amino acid-derived PET radiotracers, anti-1-amino-3-18 F-fluorocyclobutane-1-carboxylic acid ( ${ }^{18} \mathrm{~F}-\mathrm{FACBC}$ or ${ }^{18} \mathrm{~F}$-fluciclovine) has undergone the most promising translation to human use, including the availability of simplified radiosynthesis. Several studies have indicated advantageous biodistribution in the abdomen and pelvis with little renal excretion and bladder activity - characteristics beneficial for prostate cancer imaging. Studies have demonstrated improved lesion detection and diagnostic performance of ${ }^{18} \mathrm{~F}$-fluciclovine in comparison with conventional imaging, especially for recurrent prostate cancer, although issues with nonspecific uptake limit the potential role of ${ }^{18} \mathrm{~F}$-fluciclovine in the diagnosis of primary prostate cancer. Although work is ongoing, recently published intrapatient comparisons of ${ }^{18} \mathrm{~F}$-fluciclovine with ${ }^{11} \mathrm{C}$-choline reported higher overall diagnostic performance of the former, especially for the detection of disease relapse. This review is aimed at providing a detailed overview of amino acid-derived PET compounds that have been studied for use in prostate cancer imaging.

\footnotetext{
Received Feb. 27, 2016; revision accepted May 20, 2016.

For correspondence contact: David M. Schuster, Department of Radiology and Imaging Sciences, Emory University, Room E152, 1364 Clifton Rd., Atlanta, GA 30322.

E-mail: dschust@emory.edu

COPYRIGHT ( $) 2016$ by the Society of Nuclear Medicine and Molecular Imaging, Inc.
}

Key Words: ${ }^{18} \mathrm{~F}$-fluciclovine; prostate; ${ }^{18} \mathrm{~F}-\mathrm{FACBC}$; amino acid

J Nucl Med 2016; 57:61S-66S

DOI: 10.2967/jnumed.115.170209

$A_{\text {mino acids serve many physiologic roles, including acting as }}$ the basic building blocks of protein, as components in energy metabolism, and as precursors of bioactive molecules $(1,2)$. Amino acid transport is upregulated in carcinomas because of increased amino acid use for energy requirements and protein synthesis (2-4). Therefore, the molecular imaging of amino acid activity is an attractive target, especially in situations in which ${ }^{18}$ F-FDG PET has limitations, such as in the detection of prostate cancer (5-7). Amino acid-based radiotracer cancer imaging with both naturally occurring and synthetic radiolabeled amino acids chiefly reflects substrate transport across the tumor cell membrane $(1,2,8)$.

Amino acids are transported across plasma membranes by proteins that are encoded by members of the solute carrier family of genes (1). Specific amino acid transporters that are overexpressed in prostate cancer include system L amino acid transporters (LAT1, LAT3, and LAT4), system alanine-serine-cysteine transporters (ASCT1 and ASCT2), the system A sodium-coupled neutral amino acid transporter, system $\mathrm{X}^{-} \mathrm{c}$, system $\mathrm{B}^{0,+}$, and proton-assisted transporters (PAT1 and PAT4) (9-18). Of these amino acid transporters, ASCT2 and LAT1 appear to be the most important in cancer metabolism and have been described as "partners in crime" $(3,10)$. LAT1 expression in prostate cancer specimens has been correlated with poor survival and an elevated Gleason score $(13,14)$. ASCT2 expression has also been associated with more aggressive behavior of prostate cancer, and the expression of both ASCT2 and LAT3 has been shown to be stimulated by androgen signaling in androgen-dependent prostate cancer (19-21).

In many cancers, including prostate cancer, a metabolic shift occurs when glutamine is used as an alternative energy source, instead of glucose $(4,22)$. Targeting ASCT2 transport of glutamine inhibits prostate cancer growth in vitro and in PC-3 xenografts in nude mice (22). Changes in glutamine metabolic activity in prostate cancer appear to be related to v-myc avian myelocytomatosis viral oncogene homolog $(M Y C)$ protein overexpression, and both leucine and glutamine are important factors in mammalian target of rapamycin feedback signaling in cancer $(1,10,20,22-24)$. Interestingly, preclinical data have suggested that metformin-induced suppression of glucose oxidation in tandem with glutamine inhibition reduces cellular proliferation in prostate cancer (25). 


\section{INVESTIGATIONS WITH RADIOLABELED NATURALLY OCCURRING AMINO ACIDS}

Radiolabeled naturally occurring amino acids, such as $\mathrm{L}^{-1}{ }^{11} \mathrm{C}-$ methionine $\left({ }^{11} \mathrm{C}-\mathrm{MET}\right)$ and $\mathrm{L}-1-{ }^{11} \mathrm{C}-5$-hydroxytryptophan, were the first radiotracers used in amino acid-based molecular imaging of prostate cancer (26-29).

A pharmacokinetic study was performed on 10 patients who had castration-resistant cancer and progressive or new lesions on bone scans and who underwent PET imaging with ${ }^{11} \mathrm{C}-\mathrm{MET}$ and ${ }^{18}$ F-FDG (26). Higher uptake in index skeletal lesions with ${ }^{11} \mathrm{C}$ MET than with ${ }^{18} \mathrm{~F}$-FDG, more rapid blood clearance of ${ }^{11} \mathrm{C}-\mathrm{MET}$, and lower (potentially interfering) urinary excretion of ${ }^{11} \mathrm{C}-\mathrm{MET}$ were observed. In a subsequent study of 12 patients with rising prostate-specific antigen (PSA) levels and progressive disease, ${ }^{11} \mathrm{C}-\mathrm{MET}$ was noted to be more sensitive than ${ }^{18} \mathrm{~F}$-FDG: ${ }^{11} \mathrm{C}$ MET and ${ }^{18} \mathrm{~F}-\mathrm{FDG}$ detected $72.1 \%$ (251/348) and 48\% (167/348) of bone and soft-tissue lesions, respectively (27). Figure 1 shows an example of ${ }^{11} \mathrm{C}$-MET PET imaging of prostate cancer.

In a study of primary prostate cancer, a cohort of 20 subjects with mean PSA levels of $9.36 \mathrm{ng} / \mathrm{mL}$ and negative repeat biopsies underwent ${ }^{11} \mathrm{C}$-MET PET. Suspect ${ }^{11} \mathrm{C}$-MET uptake was noted in $75 \%$ of subjects $(15 / 20), 46.7 \%$ of whom $(7 / 15)$ had prostate cancer confirmed by ${ }^{11} \mathrm{C}-\mathrm{MET}$-guided biopsy (28). However, the fact that 8 subjects with focal ${ }^{11} \mathrm{C}$-MET uptake and negative guided biopsies had either benign prostatic hyperplasia $(6 / 8)$ or chronic prostatitis $(2 / 8)$ demonstrates a limitation in the evaluation of primary prostate cancer. In a more recent study, 20 patients with suspected primary prostate cancer underwent both ${ }^{11} \mathrm{C}$-MET and dual-phase (60- and 120-min) ${ }^{18} \mathrm{~F}-\mathrm{FDG}$ PET/CT (30). Although for a Gleason score of 8 or greater there was no significant difference between ${ }^{11} \mathrm{C}$-MET PET and ${ }^{18} \mathrm{~F}$-FDG PET, ${ }^{11} \mathrm{C}$-MET had greater sensitivity than ${ }^{18} \mathrm{~F}-\mathrm{FDG}$ for the detection of cancers with Gleason scores of 6 and 7.

The neurotransmitter amine precursor 5-hydroxytryptophan has also been studied because neuroendocrine differentiation in prostatic adenocarcinoma is linked to high-grade and refractory disease $(31,32)$. A report on $\mathrm{L}-1-{ }^{11} \mathrm{C}-5$-hydroxytryptophan in a cohort of 10 subjects with castration-resistant prostate cancer showed that $\mathrm{L}-1-{ }^{11} \mathrm{C}-5$-hydroxytryptophan PET may be useful in

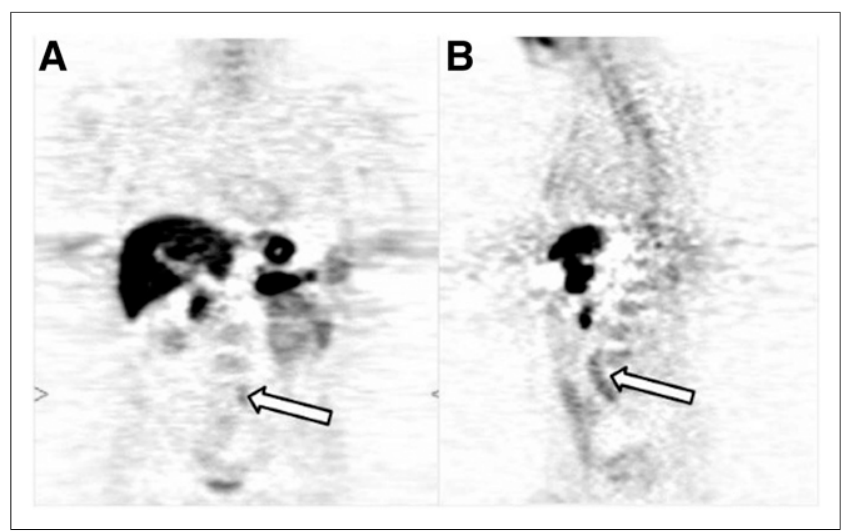

FIGURE 1. Coronal (A) and sagittal (B) PET images demonstrating ${ }^{11} \mathrm{C}-\mathrm{MET}$ uptake in prostate cancer retroperitoneal nodal metastasis (arrows). Note intense physiologic hepatic and pancreatic activities. (Images courtesy of Steve Larson, Memorial Sloan Kettering Cancer Center, and Homer Macapinlac, M.D. Anderson Cancer Center.) the diagnosis and monitoring of treatment of metastatic castrationresistant prostatic adenocarcinoma (29).

\section{SYNTHETIC OR NON-NATURALLY OCCURRING PET RADIOTRACERS}

Early work with radiolabeled naturally derived amino acid PET radiotracers set the stage for the investigation of synthetic or nonnaturally occurring amino acid PET radiotracers for the imaging of prostate cancer. The advantages of these radiotracers include the potential for radiolabeling with ${ }^{18} \mathrm{~F}$, simplified radiosynthesis, and more straightforward kinetics because of the lack of accumulation of metabolites (1).

The most comprehensive work to date with a synthetic amino acid PET radiotracer for prostate cancer imaging has been conducted with anti-1-amino-3- ${ }^{18} \mathrm{~F}$-fluorocyclobutane-1-carboxylic acid ( ${ }^{18} \mathrm{~F}-\mathrm{FACBC}$ or ${ }^{18} \mathrm{~F}$-fluciclovine) (33). (The standard international nomenclature for this radiotracer is ${ }^{18} \mathrm{~F}$-fluciclovine; therefore, ${ }^{18} \mathrm{~F}$-fluciclovine is used in this review.) ${ }^{18} \mathrm{~F}$-labeled 1-amino-cycloalkane-1-carboxylic acids such as ${ }^{18} \mathrm{~F}$-fluciclovine are a class of $\alpha, \alpha$-dialkyl amino acids that have a fluorine atom on the side chain, that are covalently bonded to each other to form a cyclic ring, and that are neither metabolized nor incorporated into proteins $(3,12,34-36)$.

Initial preclinical experiments with ${ }^{18} \mathrm{~F}$-fluciclovine reported in vitro uptake in DU145 prostate carcinoma cells and that radiotracer transport was most like that of leucine via system L, especially LAT1 $(34,37)$. Subsequent studies demonstrated that system alanineserine-cysteine transporters-specifically, ASCT2-play the largest role in ${ }^{18} \mathrm{~F}$-fluciclovine transport; however, in a more acidic intratumoral environment, LAT1 transport is relatively elevated $(12,35,38)$. Ono postulated that as a tumor progresses into castration resistance, LAT1 transport of ${ }^{18} \mathrm{~F}$-fluciclovine becomes more active (38). The predominance of ASCT2-mediated cellular influx and efflux suggests that ${ }^{18} \mathrm{~F}$-fluciclovine transport is more similar to that of glutamine than to that of leucine (39). In vitro studies demonstrated that ${ }^{18} \mathrm{~F}$-fluciclovine uptake is enhanced in $\mathrm{LNCaP}$ (androgen receptor-positive) but not DU145 (androgen receptornegative) cell lines in response to androgen stimulation and that, in both prostate cancer cell lines, relative ${ }^{18} \mathrm{~F}$-fluciclovine uptake is greater than that of methionine, choline, and acetate (21). Work with a rat orthotopic prostate cancer model showed that, compared with ${ }^{18} \mathrm{~F}$-FDG, ${ }^{18} \mathrm{~F}$-fluciclovine better visualized the tumor with a significantly lower level of accumulation in the bladder (34).

Human dosimetry studies with ${ }^{18} \mathrm{~F}$-fluciclovine described a commonality of biodistribution with other amino acid radiotracers, such as ${ }^{11} \mathrm{C}$-MET (40-42). Physiologic ${ }^{18} \mathrm{~F}$-fluciclovine activity shows the highest intensity in the pancreas and liver; moderate, heterogeneous intensity in the marrow, salivary glands, lymphoid tissue, and pituitary; and variable intensity in the bowel (Fig. 2). Brain parenchyma activity is minimal, and in most patients, bladder activity is absent or mild (43). Compared with ${ }^{11} \mathrm{C}-\mathrm{MET},{ }^{18} \mathrm{~F}$-fluciclovine seems to have more rapid pancreatic clearance and comparatively lower levels of renal and bladder activity.

The initial visualization of metastatic prostate cancer nodal disease with ${ }^{18} \mathrm{~F}$-fluciclovine took place fortuitously during a study of renal lesions (44). A subsequent pilot study in 9 patients with primary prostate carcinoma and 6 patients with suspected recurrence reported promising results, including the visualization of the tumor despite negative ${ }^{111}$ In-capromab-pendetide findings (45). Time-activity curves typically peak at 5-20 min, with subsequent 


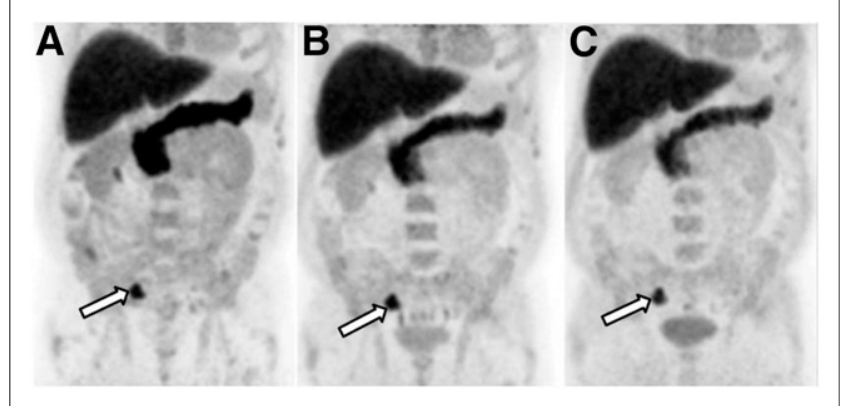

FIGURE 2. Multiple-time-point anterior projection images of typical ${ }^{18} \mathrm{~F}$-fluciclovine biodistribution at 5-16 $\mathrm{min}(\mathrm{A}), 17-28 \mathrm{~min}(\mathrm{~B})$, and 29 $40 \mathrm{~min}(\mathrm{C})$. Note activity in metastatic right pelvic node (arrows) and typical absent to minimal bladder activity.

washout; therefore, early imaging is recommended. Although most work to date has involved the use of ${ }^{18} \mathrm{~F}$-fluciclovine PET for recurrent disease, investigators have also reported the results of studies for primary disease and initial staging.

\section{PRIMARY PROSTATE CANCER DIAGNOSIS AND INITIAL STAGING}

For primary prostate cancer, the challenges of using ${ }^{18} \mathrm{~F}$-fluciclovine PET are similar to those reported with ${ }^{11} \mathrm{C}$-MET PET. In a study of 10 patients with primary prostate carcinoma, although the $\mathrm{SUV}_{\max }$ was significantly higher in malignant sextants than in nonmalignant sextants and the Gleason score generally correlated with the $\mathrm{SUV}_{\max }$, overlap of the $\mathrm{SUV}_{\max }$ in the benign and malignant sextants limited the utility of ${ }^{18} \mathrm{~F}$-fluciclovine PET for radiotherapy planning (46). In a prospective study of 21 patients with primary prostate cancer and with whole-mount step-section analysis as a reference standard, Turkbey et al. reported that although the activity of ${ }^{18} \mathrm{~F}$-fluciclovine was significantly higher in prostate cancer than in normal prostate, ${ }^{18} \mathrm{~F}$-fluciclovine did not discriminate malignancy from benign prostatic hyperplasia (47). Interestingly, although a sector-based analysis of ${ }^{18} \mathrm{~F}$-fluciclovine demonstrated a sensitivity of $67 \%$ and a specificity of $66 \%-$ values inferior to the $73 \%$ sensitivity and $79 \%$ specificity of T2weighted MRI - the highest positive predictive value (PPV), $82 \%$, was achieved with a combination of ${ }^{18} \mathrm{~F}$-fluciclovine and MRI for tumor localization.

In a report of a multicenter phase $2 b$ clinical trial for the staging of primary prostate cancer, 68 patients with a mean PSA level of $88.6 \mathrm{ng} / \mathrm{mL}$ underwent both whole-body ${ }^{18} \mathrm{~F}$-fluciclovine PET/CT and conventional imaging with $\mathrm{CT}$ and bone scanning (48). Overall similar accuracies-85.5\% and $87.3 \%$-were reported for ${ }^{18} \mathrm{~F}-$ fluciclovine PET/CT and conventional imaging, respectively. However, in 13 patients (23 regions), ${ }^{18} \mathrm{~F}$-fluciclovine PET was positive for nodes 5-9 $\mathrm{mm}$ in short-axis diameter that were not detected by CT, and in 7 patients, ${ }^{18} \mathrm{~F}$-fluciclovine PET was positive for skeletal lesions that were not detected by conventional imaging, although these results were not confirmed with the study reference standard. Of note, neither modality detected nodal metastases $5 \mathrm{~mm}$ or smaller in 7 patients who underwent prostatectomy and extended lymph node dissection. Other groups have also studied the kinetics of ${ }^{18} \mathrm{~F}$-fluciclovine in primary prostate cancer and the detection of untreated metastatic prostate cancer in an early-phase study, with encouraging results $(49,50)$.

\section{RECURRENT PROSTATE CANCER DETECTION AND STAGING}

${ }^{18} \mathrm{~F}$-fluciclovine PET seems to be most useful in patients with biochemical failure and suspected recurrent disease. In a single-center trial at Emory University of patients with biochemical failure and negative bone scan results, 53 patients underwent ${ }^{18} \mathrm{~F}$-fluciclovine $\mathrm{PET} / \mathrm{CT}$ and routine clinical CT (30 with and 23 without intravenous contrast material) within a 90-d interval. The scan positivity rates for recurrent disease were $77.4 \%$ (41/53) for ${ }^{18} \mathrm{~F}$-fluciclovine and $18.9 \%$ (10/53) for CT (51). The positivity rates varied with absolute PSA levels: $37.5 \%$ at PSA levels of less than $1 \mathrm{ng} / \mathrm{mL}, 77.8 \%$ at PSA levels of $1-2 \mathrm{ng} / \mathrm{mL}, 91.7 \%$ at PSA levels of greater than $2-5 \mathrm{ng} / \mathrm{mL}$, and $83.3 \%$ at PSA levels of greater than $5 \mathrm{ng} / \mathrm{mL}$. The respective CT positivity rates were $12.5 \%, 0.0 \%, 41.7 \%$, and $16.7 \%$. In addition, the positivity rate was greater with a shorter doubling time and with a higher original Gleason score. Significantly higher sensitivity was also reported for prostate or prostate bed disease and extraprostatic disease in a subset analysis of patients who underwent CT with intravenous contrast material as a comparator. In a retrospective study at a different center of 30 scans in 26 patients with suspected or proven recurrence, $53.3 \%$ of ${ }^{18} \mathrm{~F}$-fluciclovine studies were positive, and the detection of disease was positively correlated with absolute PSA levels and negatively correlated with PSA doubling times (52). Schuster et al. had reported earlier that, on the basis of logistic regression, a patient with a PSA level of $1 \mathrm{ng} / \mathrm{mL}$ had a $71.8 \%$ probability of positive ${ }^{18} \mathrm{~F}$-fluciclovine scan results, but optimal PSA trigger values have yet to be defined (53).

In published reports from the Emory University trial mentioned earlier, ${ }^{18} \mathrm{~F}$-fluciclovine imaging demonstrated superior diagnostic performance compared with ${ }^{111}$ In-capromab-pendetide in a comprehensive analysis of 93 patients for whom both studies were obtained within $90 \mathrm{~d}(53,54)$. A strength of that trial was that histologic proof of the presence of disease on a per-patient basis was established for $96.1 \%$ of index lesions. For the 91 of 93 patients for whom a reference standard was established for the prostate or prostate bed, ${ }^{18} \mathrm{~F}$-fluciclovine PET had $90.2 \%$ sensitivity, $40.0 \%$ specificity, $73.6 \%$ accuracy, $75.3 \% \mathrm{PPV}$, and $66.7 \%$ negative predictive value. The respective values for ${ }^{111}$ In-capromab pendetide were $67.2 \%, 56.7 \%, 63.7 \%, 75.9 \%$, and $45.9 \%$. For the 70 of 93 patients for whom a reference standard was established for the presence or absence of extraprostatic disease, ${ }^{18} \mathrm{~F}$-fluciclovine PET had $55.0 \%$ sensitivity, $96.7 \%$ specificity, $72.9 \%$ accuracy, $95.7 \% \mathrm{PPV}$, and $61.7 \%$ negative predictive value. The respective values for ${ }^{111}$ In-capromab pendetide were $10.0 \%, 86.7 \%, 42.9 \%$, $50.0 \%$, and $41.9 \%$. Overall, ${ }^{18} \mathrm{~F}$-fluciclovine PET detected 14 more patients with prostate or prostate bed recurrence (55 vs. 41) and 18 more patients with extraprostatic involvement (22 vs. 4), resulting in upstaging for $25.7 \%$ of patients. Malignant lymph nodes ranging from $0.5 \times 0.5$ to $2.3 \times 2 \mathrm{~cm}$ were detected.

Figure 3 shows an example of local recurrence detection with ${ }^{18}$ F-fluciclovine. Detection of retroperitoneal nodal disease and utility with skeletal lesions are shown in Figure 4 and Figure 5, respectively.

\section{COMPARISON WITH CHOLINE FOR DETECTION AND RESTAGING OF RECURRENT DISEASE}

Choline is a substrate for the synthesis of phosphatidylcholine, which is the major phospholipid in the cell membrane (55). Choline kinase activity is substantially upregulated in tumor cells (56), especially in prostate cancer. Consequently, ${ }^{11} \mathrm{C}$-choline PET and ${ }^{18}$ F-choline PET have been widely used for prostate cancer imaging, 


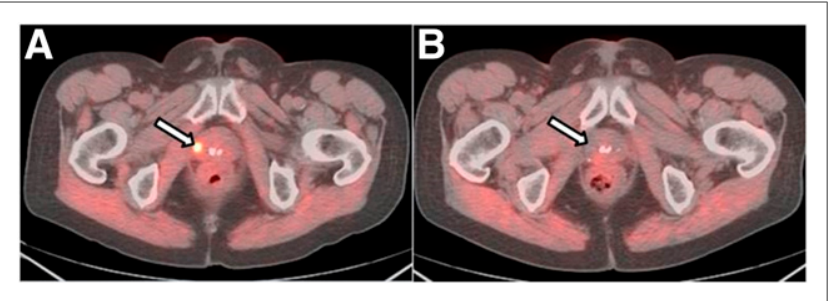

FIGURE 3. Axial coregistered ${ }^{18} \mathrm{~F}$-fluciclovine PET/CT images demonstrating biopsy-proven prostate cancer recurrence (arrow) after radiotherapy (A) and absence of activity at site of lesion (arrow) after cryotherapy (B).

particularly for prostate cancer relapse detection. Therefore, comparing the performance of promising radiolabeled amino acid analogs, such as ${ }^{18} \mathrm{~F}$-fluciclovine, with that of choline for the detection of prostate cancer is of interest, especially for patients with relapse. Because of variance in patient inclusion criteria and reference standards, making this determination from the literature alone is problematic; therefore, a trial directly comparing radiotracers in the same patient is preferable. In a recently completed study at the University of Bologna, 100 patients with biochemical failure after radical treatment underwent ${ }^{11} \mathrm{C}$-choline PET and ${ }^{18} \mathrm{~F}$ fluciclovine PET within $1 \mathrm{wk}$. The results of preliminary, interim, and final analyses from this trial have been published (57-59).

In the preliminary analysis of 15 patients, ${ }^{18} \mathrm{~F}$-fluciclovine had a better detection rate than ${ }^{11} \mathrm{C}$-choline in patient-based and lesion-based analyses (57). Findings from this early report were confirmed through an interim analysis (58). A final report from this trial for 89 patients for whom the reference standard of clinical follow-up for at least $1 \mathrm{y}$ was available provided a complete description of diagnostic performance (59). In this analysis, choline and ${ }^{18} \mathrm{~F}$-fluciclovine had sensitivities of $32 \%$ and $37 \%$, specificities of $40 \%$ and $67 \%$, accuracies of $32 \%$ and $38 \%$, PPVs of $90 \%$ and $97 \%$, and negative predictive values of $3 \%$ and $4 \%$, respectively; these results

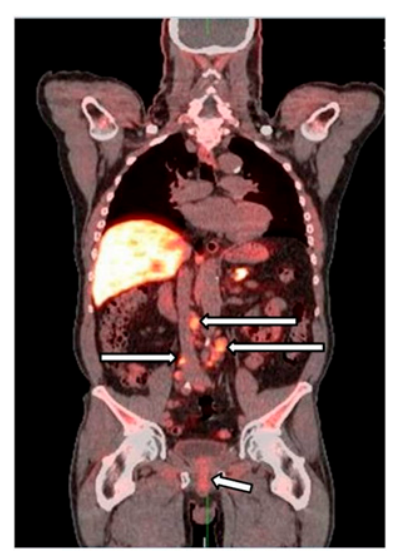

FIGURE 4. Coronal coregistered ${ }^{18} \mathrm{~F}$-fluciclovine PET/CT image demonstrating extensive retroperitoneal nodal prostate cancer metastasis (long arrows) and mild background activity in prostate after therapy (short arrow). (Image courtesy of Trond Bogsrud, Oslo University Hospital, Oslo, Norway.) fluciclovine over ${ }^{11} \mathrm{C}$-choline; these included more favorable biodistribution, with lower background activity in the abdomen and pelvis, and - of course - a longer half-life. No similar comparison of ${ }^{18} \mathrm{~F}$-fluciclovine with ${ }^{18} \mathrm{~F}$-choline has been reported, but the overall accuracies of ${ }^{11} \mathrm{C}$ choline and ${ }^{18} \mathrm{~F}$-choline have been noted to be equivalent $(60)$.

A New Drug Application filing for ${ }^{18} \mathrm{~F}$-fluciclovine for the detection of recurrent prostate carcinoma was accepted by the U.S. Food and Drug Administration for priority review on the basis of data from more than 700 prostate cancer patients imaged in the United States, Norway, and Italy. Subsequently, in May 2016, approval was granted for the indication of suspected recurrent prostate cancer in patients with elevated PSA after prior therapy (61). Industry-sponsored phase $3 \mathrm{~b}$ trials in the United States and the United Kingdom are ongoing. In our experience, ${ }^{18} \mathrm{~F}$-fluciclovine PET may be most useful for the detection of small and borderline nodes in the range of $5-15 \mathrm{~mm}$ and for occult skeletal lesions not detected by conventional imaging, with a lower sensitivity for blastic skeletal lesions than for mixed and lytic or silent lesions (43).

\section{EMERGING AMINO ACID-BASED PET RADIOTRACERS}

Other PET radiotracers derived from naturally occurring and synthetic amino acids are in various stages of preclinical and early clinical investigations. The development of fluorinated methionine and tryptophan derivatives has been reported (62-64). In addition, ${ }^{11} \mathrm{C}$ and ${ }^{18} \mathrm{~F}$ system $\mathrm{A}$ transport radiotracers have been tested in preclinical prostate cancer animal models and are in the early stages of human translation $(3,65,66)$. A homolog of ${ }^{18} \mathrm{~F}$-fluciclovine, anti-1-amino-2- ${ }^{18}$ F-fluorocyclopentane-1-carboxylic acid ( $\left.{ }^{18} \mathrm{~F}-\mathrm{FACPC}\right)$, had been evaluated as a prostate cancer imaging agent in humans. However, despite promising preclinical data, the results for 5 patients who underwent both ${ }^{18} \mathrm{~F}$-FACPC PET and ${ }^{18} \mathrm{~F}$-fluciclovine PET demonstrated suboptimal disease conspicuity with ${ }^{18} \mathrm{~F}$ FACPC relative to that with ${ }^{18} \mathrm{~F}$-fluciclovine; these findings served as an example of the challenge of translation from the bench to the bedside $(67,68)$. Cationic transport with $O-2\left(\left(2-{ }^{18} \mathrm{~F}\right.\right.$-fluoroethyl $)$ methyl-amino)ethyltyrosine has been studied as a probe for system $\mathrm{B}^{0,+}$ transport within prostate cancer PC3 cells and mice xenografts, with good results (18).

Glutamate, glutamine, and glutamic acid PET radiotracers have been developed (69). Progress has been made with a system $\mathrm{X}^{-} \mathrm{c}$ glutamate derivative PET radiotracer, $(4 S)-4-\left(3-{ }^{18} \mathrm{~F}\right.$-fluoropropyl)L-glutamate $\left({ }^{18} \mathrm{~F}-\mathrm{FSPG}\right)$, with which primary prostate cancer in 5 of 10 patients and recurrent or metastatic prostate cancer in 7 of 10

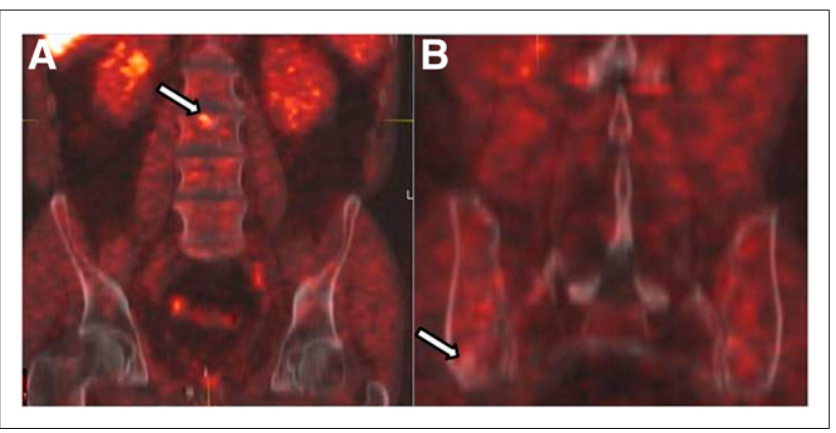

FIGURE 5. (A) Coronal coregistered ${ }^{18} \mathrm{~F}$-fluciclovine PET/CT images demonstrating focal activity located in mixed lytic-sclerotic lesion near vertebral end plate and proven to represent metastasis (arrow). (B) No activity was present in purely blastic metastasis (arrow). 


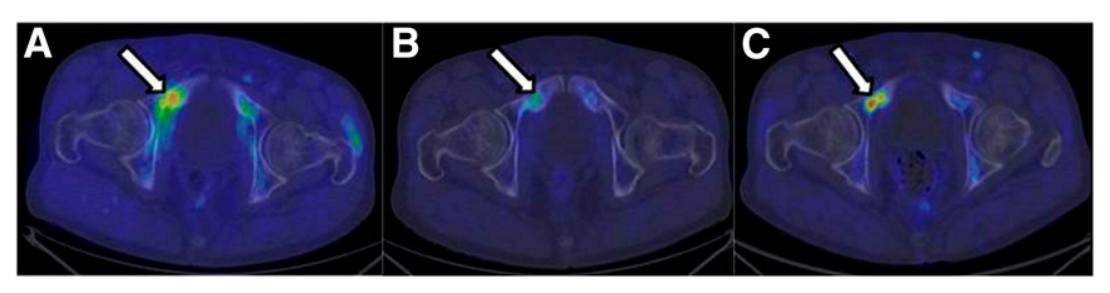

FIGURE 6. (A and $B$ ) Coregistered ${ }^{18} \mathrm{~F}$-fluciclovine axial PET/CT image (A) with definitively positive findings in right pubic ramus (arrow) and ${ }^{11} \mathrm{C}$-choline PET/CT image (B) with mild nonspecific asymmetry at same location (arrow). (C) ${ }^{11} \mathrm{C}$-choline PET/CT findings became positive $1 \mathrm{y}$ later (arrow).

patients were successfully visualized (70). Finally, although not specifically yet studied with prostate cancer, immuno-PET imaging with radiotracers such as ${ }^{89} \mathrm{Zr}$-DFO-Ab2, targeting the extracellular domain of LAT1, enable direct interrogation of the amino acid transport complex itself $(8)$.

\section{CONCLUSION}

The upregulation of amino acid transport in prostate cancer and the interrelationship of the intracellular amino acid pool with tumor signaling provide the biologic underpinnings of the molecular imaging of prostate cancer with amino acid-based radiotracers. Although initial work had been completed with PET radiotracers derived from naturally occurring amino acids, most progress has been made with radiotracers based on non-naturally occurring amino acids, such as ${ }^{18} \mathrm{~F}$-fluciclovine. On the basis of clinical data to date, the detection of recurrent locoregional disease and the distant spread of disease, rather than the detection of primary prostate cancer, seem to be the most promising applications for this class of radiotracers. Further study to determine utility in various clinical situations beyond disease detection, such as the response to therapy and imaging-guided treatment modulation, is ongoing.

\section{DISCLOSURE}

The authors have participated in sponsored research involving ${ }^{18} \mathrm{~F}$ fluciclovine, among other radiotracers. Emory University and Dr. Mark Goodman are eligible to receive royalties for ${ }^{18} \mathrm{~F}$-fluciclovine. No other potential conflict of interest relevant to this article was reported.

\section{REFERENCES}

1. Huang C, McConathy J. Radiolabeled amino acids for oncologic imaging. J Nucl Med. 2013;54:1007-1010.

2. Jager PL, Vaalburg W, Pruim J, de Vries EG, Langen KJ, Piers DA. Radiolabeled amino acids: basic aspects and clinical applications in oncology. J Nucl Med. 2001;42:432-445

3. McConathy J, Yu W, Jarkas N, Seo W, Schuster DM, Goodman MM. Radiohalogenated nonnatural amino acids as PET and SPECT tumor imaging agents. Med Res Rev. 2012;32:868-905.

4. Nakanishi T, Tamai I. Solute carrier transporters as targets for drug delivery and pharmacological intervention for chemotherapy. J Pharm Sci. 2011;100:3731-3750.

5. Wibmer AG, Burger IA, Sala E, Hricak H, Weber WA, Vargas HA. Molecular imaging of prostate cancer. Radiographics. 2016;36:142-159.

6. Yu CY, Desai B, Ji L, Groshen S, Jadvar H. Comparative performance of PET tracers in biochemical recurrence of prostate cancer: a critical analysis of literature. Am J Nucl Med Mol Imaging. 2014;4:580-601.

7. Schöder H, Herrmann K, Gonen M, et al. 2-[18 F]fluoro-2-deoxyglucose positron emission tomography for the detection of disease in patients with prostate-specific antigen relapse after radical prostatectomy. Clin Cancer Res. 2005;11:4761-4769.
8. Ikotun $\mathrm{OF}$, Marquez BV, Huang $\mathrm{C}$, et al. Imaging the L-type amino acid transporter-1 (LAT1) with Zr-89 immunoPET. PLoS One. 2013;8:e77476.

9. Heublein S, Kazi S, Ogmundsdottir MH, et al. Proton-assisted amino-acid transporters are conserved regulators of proliferation and amino-acid-dependent mTORC1 activation. Oncogene. 2010;29:4068-4079.

10. Fuchs BC, Bode BP. Amino acid transporters ASCT2 and LAT1 in cancer: partners in crime? Semin Cancer Biol. 2005;15:254-266.

11. Smolarz K, Krause BJ, Graner FP, et al. (S)-4-(3- ${ }^{18}$ Ffluoropropyl)-L-glutamic acid: an ${ }^{18} \mathrm{~F}$-labeled tumorspecific probe for PET/CT imaging-dosimetry. J Nucl Med. 2013;54:861-866.

12. Okudaira H, Shikano N, Nishii R, et al. Putative transport mechanism and intracellular fate of trans-1-amino${ }^{3-18} \mathrm{~F}$-fluorocyclobutanecarboxylic acid in human prostate cancer. J Nucl Med. 2011;52:822-829.

13. Sakata T, Ferdous G, Tsuruta T, et al. L-type amino-acid transporter 1 as a novel biomarker for high-grade malignancy in prostate cancer. Pathol Int. 2009;59:7-18.

14. Segawa A, Nagamori S, Kanai Y, Masawa N, Oyama T. L-type amino acid transporter 1 expression is highly correlated with Gleason score in prostate cancer. Mol Clin Oncol. 2013;1:274-280.

15. Cole KA, Chuaqui RF, Katz K, et al. cDNA sequencing and analysis of POV1 (PB39): a novel gene up-regulated in prostate cancer. Genomics. 1998; 51:282-287.

16. Wang Q, Tiffen J, Bailey CG, et al. Targeting amino acid transport in metastatic castration-resistant prostate cancer: effects on cell cycle, cell growth, and tumor development. J Natl Cancer Inst. 2013;105:1463-1473.

17. Chuaqui RF, Englert CR, Strup SE, et al. Identification of a novel transcript upregulated in a clinically aggressive prostate carcinoma. Urology. 1997;50:302-307.

18. Müller A, Chiotellis A, Keller C, et al. Imaging tumour ATB0,+ transport activity by PET with the cationic amino acid $O-2\left(\left(2-\left[{ }^{18} \mathrm{~F}\right]\right.\right.$ fluoroethyl)methylamino)ethyltyrosine. Mol Imaging Biol. 2014;16:412-420.

19. Li R, Younes M, Frolov A, et al. Expression of neutral amino acid transporter ASCT2 in human prostate. Anticancer Res. 2003;23:3413-3418.

20. Wang Q, Bailey CG, Ng C, et al. Androgen receptor and nutrient signaling pathways coordinate the demand for increased amino acid transport during prostate cancer progression. Cancer Res. 2011;71:7525-7536.

21. Okudaira H, Oka S, Ono M, et al. Accumulation of trans-1-amino-3-[ $\left.{ }^{18} \mathrm{~F}\right]$ fluorocyclobutanecarboxylic acid in prostate cancer due to androgen-induced expression of amino acid transporters. Mol Imaging Biol. 2014;16:756-764.

22. Wang Q, Hardie RA, Hoy AJ, et al. Targeting ASCT2-mediated glutamine uptake blocks prostate cancer growth and tumour development. J Pathol. 2015; 236:278-289.

23. Gurel B, Iwata T, Koh CM, et al. Nuclear MYC protein overexpression is an early alteration in human prostate carcinogenesis. Mod Pathol. 2008;21:1156-1167.

24. Burgio SL, Fabbri F, Seymour IJ, Zoli W, Amadori D, De Giorgi U. Perspectives on mTOR inhibitors for castration-refractory prostate cancer. Curr Cancer Drug Targets. 2012;12:940-949.

25. Fendt SM, Bell EL, Keibler MA, et al. Metformin decreases glucose oxidation and increases the dependency of prostate cancer cells on reductive glutamine metabolism. Cancer Res. 2013;73:4429-4438.

26. Macapinlac HA, Humm JL, Akhurst T, et al. Differential metabolism and pharmacokinetics of $\mathrm{L}-\left[1-{ }^{11} \mathrm{C}\right]$-methionine and 2-[ $\left.{ }^{18} \mathrm{~F}\right]$ fluoro-2-deoxy-D-glucose (FDG) in androgen independent prostate cancer. Clin Positron Imaging. 1999; 2:173-181.

27. Nuñez R, Macapinlac HA, Yeung HW, et al. Combined ${ }^{18} \mathrm{~F}-\mathrm{FDG}$ and ${ }^{11} \mathrm{C}-$ methionine PET scans in patients with newly progressive metastatic prostate cancer. J Nucl Med. 2002;43:46-55.

28. Tóth G, Lengyel Z, Balkay L, Salah MA, Tron L, Toth C. Detection of prostate cancer with ${ }^{11} \mathrm{C}$-methionine positron emission tomography. J Urol. 2005;173:66-69.

29. Kälkner KM, Ginman C, Nilsson S, et al. Positron emission tomography (PET) with ${ }^{11} \mathrm{C}$-5-hydroxytryptophan (5-HTP) in patients with metastatic hormonerefractory prostatic adenocarcinoma. Nucl Med Biol. 1997;24:319-325.

30. Shiiba M, Ishihara K, Kimura G, et al. Evaluation of primary prostate cancer using ${ }^{11} \mathrm{C}$-methionine-PET/CT and ${ }^{18}$ F-FDG-PET/CT [published correction appears in Ann Nucl Med. 2012;26:146]. Ann Nucl Med. 2012;26:138-145.

31. Puccetti L, Supuran CT, Fasolo PP, et al. Skewing towards neuroendocrine phenotype in high grade or high stage androgen-responsive primary prostate cancer. Eur Urol. 2005;48:215-221.

32. di Sant'Agnese PA. Neuroendocrine differentiation in carcinoma of the prostate: diagnostic, prognostic, and therapeutic implications. Cancer. 1992;70: 254-268. 
33. Shoup TM, Olson J, Hoffman JM, et al. Synthesis and evaluation of $\left[{ }^{18} \mathrm{~F}\right] 1-$ amino-3-fluorocyclobutane-1-carboxylic acid to image brain tumors. $\mathrm{J} \mathrm{Nucl}$ Med. 1999;40:331-338.

34. Oka S, Hattori R, Kurosaki F, et al. A preliminary study of anti-1-amino-3- ${ }^{18} \mathrm{~F}-$ fluorocyclobutyl-1-carboxylic acid for the detection of prostate cancer. $\mathrm{J} \mathrm{Nucl}$ Med. 2007;48:46-55.

35. Oka S, Okudaira H, Yoshida Y, Schuster DM, Goodman MM, Shirakami Y. Transport mechanisms of trans-1-amino-3-fluoro[1-14C]cyclobutanecarboxylic acid in prostate cancer cells. Nucl Med Biol. 2012;39:109-119.

36. Washburn LC, Sun TT, Byrd B, Hayes RL, Butler TA. 1-aminocyclobutane $\left[{ }^{11} \mathrm{C}\right]$ carboxylic acid, a potential tumor-seeking agent. J Nucl Med. 1979;20:10551061 .

37. Martarello L, McConathy J, Camp VM, et al. Synthesis of syn- and anti-1amino-3- $\left[{ }^{18} \mathrm{~F}\right]$ fluoromethyl-cyclobutane-1-carboxylic acid (FMACBC), potential PET ligands for tumor detection. J Med Chem. 2002;45:2250-2259.

38. Ono M, Oka S, Okudaira $\mathrm{H}$, et al. $\left[{ }^{14} \mathrm{C}\right]$ fluciclovine (alias anti- $\left[{ }^{14} \mathrm{C}\right] \mathrm{FACBC}$ ) uptake and ASCT2 expression in castration-resistant prostate cancer cells. $\mathrm{Nucl}$ Med Biol. 2015;42:887-892.

39. Okudaira H, Nakanishi T, Oka S, et al. Kinetic analyses of trans-1-amino-3$\left[{ }^{18} \mathrm{~F}\right]$ fluorocyclobutanecarboxylic acid transport in Xenopus laevis oocytes expressing human ASCT2 and SNAT2. Nucl Med Biol. 2013;40:670-675.

40. Nye JA, Schuster DM, Yu W, Camp VM, Goodman MM, Votaw JR. Biodistribution and radiation dosimetry of the synthetic nonmetabolized amino acid analogue anti- ${ }^{18}$ F-FACBC in humans. J Nucl Med. 2007;48:1017-1020.

41. Asano Y, Inoue Y, Ikeda Y, et al. Phase I clinical study of NMK36: a new PET tracer with the synthetic amino acid analogue anti-[ $\left.{ }^{18} \mathrm{~F}\right] \mathrm{FACBC}$. Ann Nucl Med. 2011;25:414-418

42. McParland BJ, Wall A, Johansson S, Sorensen J. The clinical safety, biodistribution and internal radiation dosimetry of $\left[{ }^{18} \mathrm{~F}\right]$ fluciclovine in healthy adult volunteers. Eur J Nucl Med Mol Imaging. 2013;40:1256-1264.

43. Schuster DM, Nanni C, Fanti S, et al. Anti-1-amino- $3-{ }^{18}$ F-fluorocyclobutane-1carboxylic acid: physiologic uptake patterns, incidental findings, and variants that may simulate disease. J Nucl Med. 2014;55:1986-1992.

44. Schuster DM, Nye J, Nieh P, et al. Initial experience with the radiotracer anti-1amino-3-[F-18]fluorocyclobutane-1-carboxylic acid (anti-[F-18]FACBC) with PET in renal carcinoma. Mol Imaging Biol. 2009;11:434-438.

45. Schuster DM, Votaw J, Nieh $P$, et al. Initial experience with the radiotracer anti1-amino-3-F-18-fluorocyclobutane-1-carboxylic acid with PET/CT in prostate carcinoma. J Nucl Med. 2007;48:56-63.

46. Schuster DM, Taleghani PA, Nieh PT, et al. Characterization of primary prostate carcinoma by anti-1-amino-2-[ $\left.{ }^{18} \mathrm{~F}\right]$-fluorocyclobutane-1-carboxylic acid (anti-3$\left[{ }^{18} \mathrm{~F}\right]$ FACBC) uptake. Am J Nucl Med Mol Imaging. 2013;3:85-96.

47. Turkbey B, Mena E, Shih J, et al. Localized prostate cancer detection with ${ }^{18} \mathrm{~F}$ FACBC PET/CT: comparison with MR imaging and histopathologic analysis. Radiology. 2014;270:849-856.

48. Suzuki H, Inoue Y, Fujimoto H, et al. Diagnostic performance and safety of NMK36 (trans-1-amino-3- $\left[{ }^{18} \mathrm{~F}\right]$ fluorocyclobutanecarboxylic acid)-PET/CT in primary prostate cancer: multicenter phase IIb clinical trial. Jpn J Clin Oncol. 2016;46:152-162.

49. Sörensen J, Owenius R, Lax M, Johansson S. Regional distribution and kinetics of $\left[{ }^{18} \mathrm{~F}\right]$ fluciclovine (anti- $\left[{ }^{18} \mathrm{~F}\right] \mathrm{FACBC}$ ), a tracer of amino acid transport, in subjects with primary prostate cancer. Eur J Nucl Med Mol Imaging. 2013;40:394402.

50. Inoue Y, Asano Y, Satoh T, et al. Phase IIa clinical trial of trans-1-amino-3- ${ }^{18} \mathrm{~F}-$ fluoro-cyclobutane carboxylic acid in metastatic prostate cancer. Asia Ocean $J$ Nucl Med Biol. 2014;2:87-94.

51. Odewole OA, Tade FI, Nieh PT, et al. Recurrent prostate cancer detection with anti-3-[ ${ }^{18}$ F]FACBC PET/CT: comparison with CT. Eur J Nucl Med Mol Imaging. 2016;43:1773-1783.

52. Kairemo K, Rasulova N, Partanen K, Joensuu T. Preliminary clinical experience of trans-1-amino-3- ${ }^{18} \mathrm{~F}$-fluorocyclobutanecarboxylic acid (anti- ${ }^{18} \mathrm{~F}-\mathrm{FACBC}$ ) PET/CT imaging in prostate cancer patients. Biomed Res Int. 2014;2014:305182.
53. Schuster DM, Nieh PT, Jani AB, et al. Anti-3-[ $\left.{ }^{18} \mathrm{~F}\right]$ FACBC positron emission tomography-computerized tomography and ${ }^{111}$ In-capromab pendetide single photon emission computerized tomography-computerized tomography for recurrent prostate carcinoma: results of a prospective clinical trial. J Urol. 2014; 191:1446-1453.

54. Schuster DM, Savir-Baruch B, Nieh PT, et al. Detection of recurrent prostate carcinoma with anti-1-amino-3- ${ }^{18} \mathrm{~F}$-fluorocyclobutane-1-carboxylic acid PET/ CT and ${ }^{111}$ In-capromab pendetide SPECT/CT. Radiology. 2011;259:852-861.

55. Zeisel SH. Dietary choline: biochemistry, physiology, and pharmacology. Annu Rev Nutr. 1981;1:95-121.

56. Ackerstaff E, Pflug BR, Nelson JB, Bhujwalla ZM. Detection of increased choline compounds with proton nuclear magnetic resonance spectroscopy subsequent to malignant transformation of human prostatic epithelial cells. Cancer Res. 2001;61:3599-3603.

57. Nanni C, Schiavina R, Boschi S, et al. Comparison of ${ }^{18} \mathrm{~F}-\mathrm{FACBC}$ and ${ }^{11} \mathrm{C}$-choline $\mathrm{PET} / \mathrm{CT}$ in patients with radically treated prostate cancer and biochemical relapse: preliminary results. Eur J Nucl Med Mol Imaging. 2013;40(suppl 1):S11-S17.

58. Nanni C, Schiavina R, Brunocilla E, et al. ${ }^{18}$ F-fluciclovine PET/CT for the detection of prostate cancer relapse: a comparison to ${ }^{11} \mathrm{C}$-choline PET/CT. Clin Nucl Med. 2015;40:e386-e391.

59. Nanni C, Zanoni L, Pultrone C, et al. ${ }^{18} \mathrm{~F}-\mathrm{FACBC}$ (anti1-amino-3- ${ }^{18} \mathrm{~F}$-fluorocyclobutane-1-carboxylic acid) versus ${ }^{11} \mathrm{C}$-choline $\mathrm{PET} / \mathrm{CT}$ in prostate cancer relapse: results of a prospective trial. Eur J Nucl Med Mol Imaging. 2016;43: 1601-1610.

60. Brogsitter C, Zophel K, Kotzerke J. ${ }^{18} \mathrm{~F}$-choline, ${ }^{11} \mathrm{C}$-choline and ${ }^{11} \mathrm{C}$-acetate PET/CT: comparative analysis for imaging prostate cancer patients. Eur J Nucl Med Mol Imaging. 2013;40(suppl 1):S18-S27.

61. U.S. FDA approves Blue Earth Diagnostics' AxuminTM (Fluciclovine F 18) injection after priority review for PET imaging of recurrent prostate cancer. Blue Earth Diagnostics website. http://www.blueearthdiagnostics.com/u-s-fda-approves-blueearth-diagnostics-axumintm-fluciclovine-f-18-injection-priority-review-pet-imagingrecurrent-prostate-cancer/. Published May 31, 2016. Accessed August 18, 2016.

62. Hu KZ, Wang H, Huang $\mathrm{T}$, et al. Synthesis and biological evaluation of $\mathrm{N}$-(2$\left[{ }^{18} \mathrm{~F}\right]$ fluoropropionyl)-L-methionine for tumor imaging. Nucl Med Biol. 2013; 40:926-932

63. Denoyer D, Kirby L, Waldeck K, et al. Preclinical characterization of ${ }^{18} \mathrm{~F}-\mathrm{D}-$ FPHCys, a new amino acid-based PET tracer. Eur J Nucl Med Mol Imaging. 2012;39:703-712.

64. Chiotellis A, Mu L, Muller A, et al. Synthesis and biological evaluation of ${ }^{18} \mathrm{~F}-$ labeled fluoropropyl tryptophan analogs as potential PET probes for tumor imaging. Eur J Med Chem. 2013;70:768-780.

65. Yu W, McConathy J, Olson JJ, Goodman MM. System A amino acid transporttargeted brain and systemic tumor PET imaging agents 2-amino-3-[ $\left.{ }^{18} \mathrm{~F}\right]$ fluoro-2methylpropanoic acid and 3-[ $\left.{ }^{18} \mathrm{~F}\right]$ fluoro-2-methyl-2-(methylamino)propanoic acid. Nucl Med Biol. 2015;42:8-18.

66. Dunzendorfer U, Schmall B, Bigler RE, et al. Synthesis and body distribution of alpha-aminoisobutyric acid-L- ${ }^{11} \mathrm{C}$ in normal and prostate cancer-bearing rat after chemotherapy. Eur J Nucl Med. 1981;6:535-538.

67. Savir-Baruch B, Schuster DM, Jarkas N, et al. Pilot evaluation of anti-1-amino-2$\left[{ }^{18} \mathrm{~F}\right]$ fluorocyclopentane-1-carboxylic acid (anti-2-[ $\left.{ }^{18} \mathrm{~F}\right]$ FACPC) PET-CT in recurrent prostate carcinoma. Mol Imaging Biol. 2011;13:1272-1277.

68. Jarkas N, Voll RJ, Camp M, Zhang Z, Goodman MM. Characterization of the two enantiomers of anti- ${ }^{18} \mathrm{~F}-\mathrm{FACPC}$ as PET tumor agents [abstract]. J Nucl Med. 2010;51(suppl 2):306P.

69. Koglin N, Mueller A, Berndt M, et al. Specific PET imaging of $\mathrm{xC}-$ transporter activity using a ${ }^{18} \mathrm{~F}$-labeled glutamate derivative reveals a dominant pathway in tumor metabolism. Clin Cancer Res. 2011;17:6000-6011.

70. Na SJ, Mittra E, Ahn H, et al. Pilot clinical trial of (4S)-4-(3-[18 F]fluoropropyl)-Lglutamate PET in patients with prostate cancer [abstract]. J Nucl Med. 2013;54 (suppl 2):285P. 